\title{
RANCANG BANGUN SISTEM PAKAR DETEKSI PENYAKIT INFEKSI GENITALIA INTERNA
}

\author{
Ika Oktavia Pristisari ${ }^{1}$, Yan Watequlis Syaifudin ${ }^{2}$, Cahya $\operatorname{Rahmad}^{3}$ \\ ${ }^{1,2,3}$ Program Studi Teknik Informatika, Jurusan Teknologi Informasi, Politeknik Negeri Malang \\ Jl. Soekarno-Hatta No. 09 Malang 65141 \\ ${ }^{1}$ ikapriestisari@gmail.com, ${ }^{2}$ qulis@polinema.ac.id, ${ }^{3}$ cahya_rahmad@yahoo.com
}

\begin{abstract}
Abstrak
Seiring dengan perkembangan teknologi yang pesan maka manusia menemukan banyak cara demi mencapai kemudahan dalam penyelesaian masalah. Salah satunya adalah sistem pakar. Sistem pakar adalah sistem yang berusaha mengadopsi pengetahuan manusia ke komputer agar computer dapat menyelesaikan masalah seperti biasa yang dilakukan oleh para ahli.Sistem pakar yang baik dirancang agar dapt menyelesaikan suatu permaslahan tertentu dengan meniru kerja dari para ahli.

Penyakit Genitalia Interna adalah penyakit yang disebabkan oleh bakteri dapat menyerang siapa saja tak terkecuali wanita. Salah satu penyakit yang dapat menyerang wanita adalah penyakit infeksi pada genitalia interna. Penyebab penyakit ini adalah bakteri yang ada dalam organ genitalia seorang wanita. Untuk membantu seorang user yang ingin mendapatkan pengetahuan mengenai deteksi penyakit tersebut maka dibuatlah sistem pakar deteksi penyakit infeksi genitalia interna pada wanita menggunakan metode certainty factor dimana metode ini dapat menampilkan hasil deteksi berdasarkan 2 faktor yaitu ukuran keyakinan yang beasal dari pengethuan seorang pakar dan ukuran ketidakyakinan yang berasal dari user, sehingga hasil yang dihasilkan memiliki faktor keyakinan dari pihak sumber yakni pakar dan pemakai atau user.
\end{abstract}

Kata Kunci : Sistem Pakar, certainty factor

\section{Pendahuluan}

Penyakit infeksi genitalia interna pada wanita adalah penyakit yang dalam proses pendeteksiannyandeteksian penyakit ini adalah masing - masing penyakitpendeteksiannya memiliki gejala yang hampir sama satu sama lain sehingga menyebabkan kesulitan saat pendeteksiannya apabila tidak dilakukan oleh seorang pakar. Pemeriksaan penyakit ini dapat dilakukan oleh seorang pakar atau dokter ahli yang telah memiliki banyak pengalaman dalam hal kesehatan genitalia interna pada wanita sehingga penyakit yang dapat menyebabkan kemandulan pada penderitanya ini dapat dicegah. Namun dengan mudahnya pemeriksaan melalui pakar atau dokter ahli, tidak jarang pasien yang tidak memiliki waktu untuk melakukan pemeriksaan mengenai gejala yang dirasakannya kepada pakar atau dokter ahli. Selain itu juga terdapat pasien yang merasa tidak nyaman apabila harus mengkonsultasikan gejala yang dirasakannya dengan pakar / dokter ahli yang berlawanan jenis. Berawal dari permaslahan tersebut maka dibuat rancang bangun sistem pakar deteksi penyakit infeksi genitalia interna pada wanita dengan menggunakan metode certainty factor. Metode ini dapat memeberi informasi mengenai hasil deteksi penyakit dengan menunjukkan prosentase keyakinan pada hasil penyakit yang telah dideteksi berdasarkan faktor keyakinan dari seorang pakar.

\section{Penyakit Infeksi Genitalia Interna}

Penyakit yang disebabkan oleh bakteri dapat menyerang siapa saja tak terkecuali wanita. Salah satu penyakit yang dapat menyerang wanita adalah penyakit infeksi pada genitalia interna. Penyebab penyakit ini adalah bakteri yang ada dalam organ genitalia seorang wanita. Penyakit ini jika tidak segera dilakukan penanganan maka akan meyebar pada organ lainnya yang dapat menyebabkan kemandulan.Sedangkan kasus infeksi yang sangat serius dapat membahayakan jiwa penderita.

\section{Sistem Pakar}

Sistem pakar atau Expert System adalah system yang berusaha mengadosi pengetahuan manusia ke computer agar computer dapat menyelesaikan masalah seperti biasa yang dilakukan oleh para ahli.Sistem pakar yang baik dirancang agar dapt menyelesaikan suatu permaslahan tertentu dengan meniru kerja dari para ahli. Dengan sistem pakar ini, orang awam pun juga diharapkan dapat meneyelesaikan masalah yang rumit. Dimana yang sebenarnya hanya dapat diselesaikan dengan bantuan para ahli. Bagi para ahli, system pakar ini juga akan 
membantu aktivitasnya sebagai asisten yang berpengalaman.

\section{Certainty Factor}

Definisi menurut David McAllister Certainty Factor adalah suatu metode untuk membuktikan apakah suatu fakta itu pasti ataukah tidak pasti yang berbentuk metric yang biasanya digunakan dalam sistem pakar. Metode ini sangat cocok untuk sistem pakar yang mendiagnosis sesuatu yang belum pasti. Metode certainty factor ini bisa mengolah 2 bobot dalam sekali perhitungan. Untuk bobot yang lebih dari 2 banyaknya, untuk melakukan perhitungan tidak terjadi masalah apabila bobot yang dihitung teracak, artinya tidak ada aturan untuk mengkombinasikan bobotnya, karena untuk kombinasi seperti apapun hasilnya akan tetap sama(Sutojo:2008).

Persamaan 1.1. Perhitungan certainty factor. Rule 1:

IF batuk THEN penyakit $=$ batuk rejan $(\mathrm{CF}=0,8)$

Rule 2:

IF demam THEN penyakit $=$ batuk rejan $(\mathrm{CF}=0,6)$

$\mathrm{CF} 1=\mathrm{C}($ batuk $) \times \mathrm{CF}($ Rule 1$)=1 \times 0,8=0,8$

$\mathrm{CF} 2=\mathrm{C}($ demam $) \times \mathrm{CF}($ Rule2 $)=1 \times 0,6=0,6$

$\mathrm{CF}=\mathrm{CF} 1+\mathrm{CF} 2(1-\mathrm{CF} 1)=0,8+0,6(1-0,8)=0,92$

\section{Metodologi}

Metode yang digunkan dalam perancangan system ini menggunakan metode waterfall, dengan tahapan sebagai berikut :

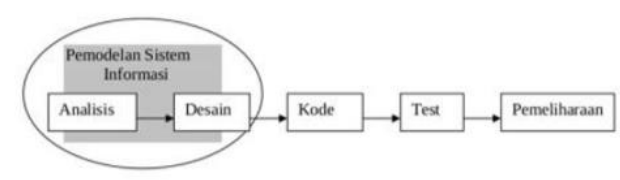

\section{Analisis dan Perancangan}

Berikut adalah usecase dan deskripsi masingmasing usecase dari rancang bangun sistem pakar deteksi penyakit infeksi genitaia interna pada wanita :

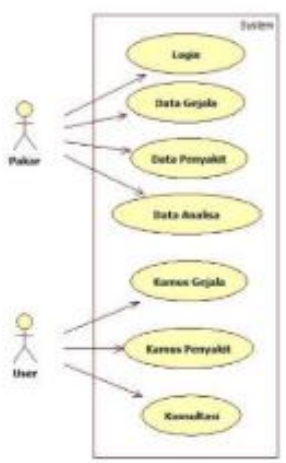

\section{Implementasi}

Tampilan halaman kosultasi yang dibuat adala sebagai berikut :

\section{Pengujian}

Penelitian yang telah dilakukan membuktikan bahwa hasil deteksi sistem dan perhitungan sudah sesuai dengan keilmuan seorang pakar dan juga perhitungan manual dengan microsoft excel.
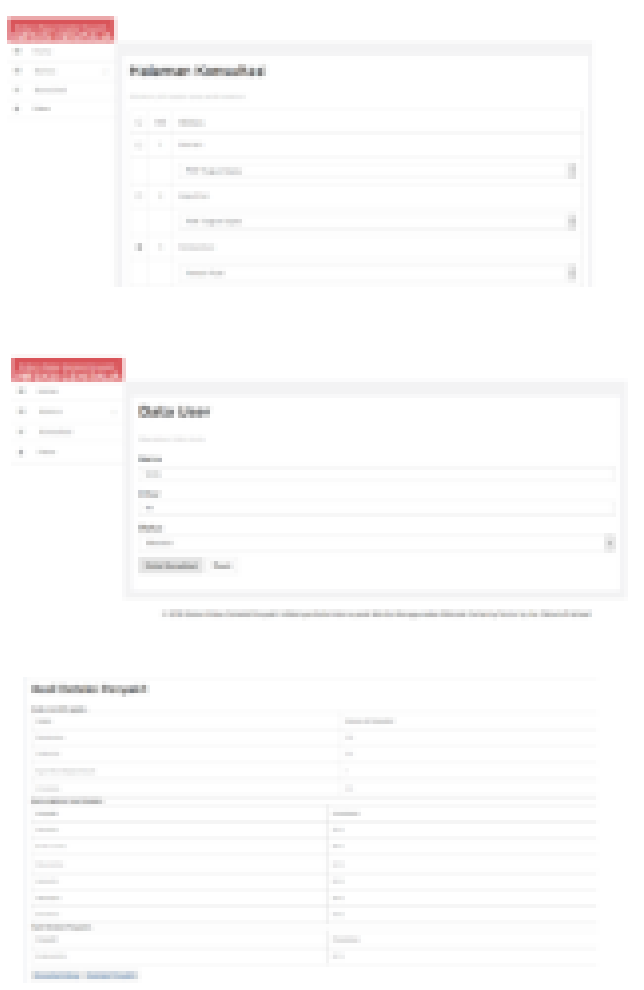

\begin{tabular}{|l|r|r|}
\hline \multicolumn{1}{|c|}{ Cervieitis } & CFPalcar & CFL'ser \\
\hline Keputihan & 0,81 & 1 \\
\hline Pesdaraban & 0,41 & 1 \\
\hline Anemin & 0,41 & 1 \\
\hline Cepat Lelah & 0,41 & 1 \\
\hline $\begin{array}{l}\text { Erat Badan } \\
\text { Menurua }\end{array}$ & 0,41 & 1 \\
\hline $\begin{array}{l}\text { Hasil } \\
\text { Perhituagan } \\
\text { Ms. Excel }\end{array}$ & \multicolumn{2}{|c|}{} \\
\hline $\begin{array}{l}\text { Hasil } \\
\text { Perhituagan } \\
\text { Sistem }\end{array}$ & \multicolumn{2}{|c}{} \\
\hline
\end{tabular}




\begin{tabular}{|c|}
\hline Grjala \\
\hline Keputihan \\
\hline Pendarahom \\
\hline Anemia \\
\hline Crpal Lelah \\
\hline Frat Badan Menuna \\
\hline Hanil Deteksi Pakar： Cervikitig \\
\hline Hasil Deteker Skstem ! Cendeith \\
\hline
\end{tabular}

\section{Kesimpulan}

Berdasarkan pembahasan yang ditulis dalam laporan skripsi ini maka dapat ditarik beberapa kesimpulan yaitu (1)Sistem yang dibuat berhasil mendeteksi penyakit berdasarkan gejala yang disampaikan saat melakukan proses konsultasi. (2)Sistem yang dibuat berhasil menampilkan hasil keyakinan dari pakar dan juga user pada saat proses konsultasi. (3)Sistem yang dibuat memiliki fasilitas kamus penyakit dan juga kamus gejala sebagai saran informasi mengenai penyakit infeksi genitalia interna pada wanita.

\section{Daftar Pustaka}

Prawirohardjo, Sarwono. Ilmu Kandungan, Edisi III.Jakarta :PT Bina Pustaka. 2011. Biranorman, Yulrio., Pangestika, Menur

Wahyu. 2013."Sistem Pakar Untuk Diagnosa Penyakit Ibu Hamil Berbasis Mobile".

Sutojo., Mulyanto, Edy., Suhartono, Vincent. Kecerdasan Buatan, Yogyakarta : ANDI Publisher. 2011.

Kadir, Abdul. Dasar Pemrograman Web Dinamis Menggunakan PHP,Edisi III.Yogyakarta : ANDI Publisher. 2008.

Hery Prasetya, Andreas. Cepat Kuasai PHP dan MySQL. Yogyakarta : ANDI Publisher. 2011. 